\title{
Use of multiple recreational drugs is associated with new HIV infections among men who have sex with men in China: a multicenter cross-sectional survey
}

Xiang Mao ${ }^{1,2,3,4}$, Sequoia I. Leuba ${ }^{5}$, Qinghai Hu ${ }^{1,2,3,4}$, Hongjing Yan ${ }^{6}$, Zhe Wang ${ }^{7}$, Lin Lu ${ }^{8}$, Minghua Zhuang ${ }^{9}$, $\mathrm{Xi}_{\mathrm{Chen}}{ }^{10}$, Jihua Fu ${ }^{11}$, Wenqing Geng ${ }^{1,2,3,4}$, Yongjun Jiang ${ }^{1,2,3,4}$, Hong Shang ${ }^{1,2,3,4^{*}}$ and Junjie $X \mathrm{u}^{1,2,3,4^{*}}$

\begin{abstract}
Background: There is limited information about the types of recreational drugs used by men who have sex with men (MSM) in China or the consequent impact on sexual health and human immunodeficiency virus (HIV) acquisition.

Methods: We recruited MSM from seven cities in China between 2012 and 2013 using multiple approaches including advertisements on gay websites, collaborating with local MSM community-based organizations, peer referrals, and venues such as gay bars and bathrooms visited by MSM. We divided participants into four subgroups based on the number of recreational drugs (RDs) used in the previous 6 months. We defined use of multiple RDs as use of $\geq 2$ types of RDs. Demographics and HIV-related high-risk behaviors were collected, and blood samples were tested for recent HIV infection by the HIV-1 subtypes B, E, and D immunoglobulin G capture enzyme immunoassay (BED-CEIA). We used multivariable logistic regression adjusted for sociodemographics to determine the adjusted odds ratios (aORs) and associated 95\% confidence intervals (Cls) of the subgroups of RD use for recent or established HIV infection.

* Correspondence: hongshang100@hotmail.com; xjjcmu@163.com

${ }^{1} \mathrm{NHC}$ Key Laboratory of AIDS Immunology (China Medical University), National Clinical Research Center for Laboratory Medicine, The First Affiliated Hospital of China Medical University, No 155, Nanjing North Street, Heping District, Shenyang 110001, Liaoning Province, China

Full list of author information is available at the end of the article

C The Author(s). 2021 Open Access This article is licensed under a Creative Commons Attribution 4.0 International License, which permits use, sharing, adaptation, distribution and reproduction in any medium or format, as long as you give appropriate credit to the original author(s) and the source, provide a link to the Creative Commons licence, and indicate if changes were made. The images or other third party material in this article are included in the article's Creative Commons licence, unless indicated otherwise in a credit line to the material. If material is not included in the article's Creative Commons licence and your intended use is not permitted by statutory regulation or exceeds the permitted use, you will need to obtain permission directly from the copyright holder. To view a copy of this licence, visit http://creativecommons.org/licenses/by/4.0/. The Creative Commons Public Domain Dedication waiver (http://creativecommons.org/publicdomain/zero/1.0/) applies to the data made available in this article, unless otherwise stated in a credit line to the data. 


\begin{abstract}
(Continued from previous page)
Results: A total of 4496 Chinese MSM participated; $28.4 \%$ used RDs, and 5\% used multiple types of RDs. The prevalence of each RD use was as follows: poppers (25.9\%), ecstasy (2.4\%), ketamine (1.2\%), amphetamine (0.6\%), tramadol (0.4\%), methamphetamine (3.8\%), and codeine (1.9\%). Users of multiple RDs commonly used poppers combined with one or more other types of RDs. Multiple RD users were likely to be aged 26-30 years (vs. 18-25 and > 30 years), live in non-local cities (vs. local cities), never married (vs. married), have a high monthly income (vs. no income and 1-599 USD), use versatile positions during anal intercourse (vs. top or bottom), and have inadequate HIV-related prevention knowledge (vs. adequate). As the number of RDs used in the previous 6 months increased, the prevalence of HIV-related high-risk behaviors increased $(P<0.05$ for all). The odds of recent HIV infection were higher among those who used one type $(\mathrm{aOR}=2.2,95 \% \mathrm{Cl}: 1.5-3.0)$ or two types of $\mathrm{RD}(\mathrm{aOR}=2.3,95 \% \mathrm{Cl}: 1.0-5.2)$ in the previous 6 months compared to the odds among those who did not use RDs.

Conclusion: The level and pattern of multiple RD use among Chinese MSM were different from high-income countries. MSM who used more RDs are more likely to engage in high-risk sexual behaviors, and these behaviors may be associated with increases in new HIV infections.
\end{abstract}

Keywords: Recreational drug use, multiple recreation drug use, Chinese MSM, Recent HIV infection, HIV-related high-risk behaviors

\section{Background}

Men who have sex with men (MSM) experience a disproportionately high burden of human immunodeficiency virus (HIV) infection [1]. The use of recreational drugs (RDs) among this population is a severe public health concern in China and elsewhere [2-4]. Unlike traditional drugs such as heroin and opium, ecstasy and methamphetamine are stimulants synthesized in laboratories. Most RDs have hallucinogenic effects and are associated with psychological dependence. RDs are challenging to quit, and excessive ingestion leads to severe consequences such as sudden death. Therefore, RDs are expressly prohibited in China [5]. At the end of the twentieth century, RD use was widespread among MSM in high-income countries [6]. This phenomenon is currently expanding to MSM communities in China and other low-to-middle income countries [3, 7-9]. RDs can enhance sexual function [10], increase sexual pleasure [11], and decrease pain during anal intercourse [12]. However, RD use has been reported to correlate with high-risk sexual behaviors and increased risk of HIV infection [11-13].

In this context, use of multiple RDs refers to using several RDs simultaneously or during the same period to achieve a particular effect. Use of multiple RDs and its correlation with HIV infection has attracted worldwide attention. Use of multiple drugs compared to use of a single drug is more likely to be associated with the transmission of HIV or other sexually transmitted infections (STIs) [14]. The use of multiple RDs alters the user's mental state and decreases cognitive inhibition [15]. This behavior leads to an increased prevalence of condomless sex (CLS), CLS with HIV-positive partners, group sex, and increased numbers of sexual partners among MSM $[16,17]$. Compared with using a single $\mathrm{RD}$, any combination of psychoactive drugs (e.g., methamphetamine, ecstasy) and physiologically active substances (e.g., poppers, erectiledysfunction agents) can increase the risk of HIV acquisition dramatically [18].

Despite the severity of this problem, most research on the use of multiple RDs has been performed in highincome countries $[2,17]$. Because of political, legal, and cultural differences, these studies' results may be generalizable to low-to-middle income countries $[8,19]$. Furthermore, HIV incidence among MSM is higher in low-to-middle income countries than in high-income countries [20], suggesting a need to study the effects of $\mathrm{RD}$ use on recent HIV infection in low-to-middle income countries.

China is the largest low-to-middle income country in the world. The HIV prevalence among Chinese MSM was $6.9 \%$ in 2019 [1,21]. By the end of 2017, there were 2.6 million drug addicts nationwide [22]. The RD use rate among Chinese MSM ranged from 24.1 to $77.1 \%$ [23-25]. Thus, it is imperative to understand the relationship between the use of multiple RDs and recent HIV infection among Chinese MSM to develop tailored interventions that limit RD use, specifically in the hopes of mitigating the HIV epidemic. The present study aims to provide researchers and clinicians with information about patterns of use of RDs among Chinese MSM and illustrate the impact of use of multiple RDs on HIV-related high-risk behaviors and HIV acquisition.

\section{Methods}

\section{Study participants and questionnaire}

To better understand the HIV epidemic among Chinese MSM, we conducted a multicenter cross-sectional survey among Chinese MSM in seven large cities in China (Shenyang, Ji'nan, Zhengzhou, Shanghai, Nanjing, 
Changsha, and Kunming) from June 2012 to June 2013. The Cruising areas and service points for MSM were used as the sampling sites. Site-specific sampling periods were determined based on attendance and hours of operation. We used several approaches to recruit participants: advertisements on gay websites, collaboration with local MSM community-based organizations, peer referrals, and venues such as gay bars and bathrooms visited by MSM. To be eligible for this study, participants had to be born male, aged 16 years or older, selfreported having anal/oral sex experiences with a male within the last year, and able to provide informed consent.

Eligible participants completed an anonymous structured questionnaire concerning sociodemographics, recent sexual behaviors, and other HIV-related high-risk behaviors: (1) demographics: age, residence, city, education, occupation, marital status, monthly income (USD), and predominant sex position in anal intercourse (AI); (2) recent sexual behaviors or HIV-related high-risk behaviors: age of sexual debut with males, the main venue of seeking male sexual partners in the previous 6 months, group sex in the previous 6 months, number of male sexual partners in the previous 6 months, commercial sex in the previous 6 months, mucosally traumatic sex in the previous 6 months, condom breaks during AI in the previous 6 months, STI-related symptoms in the previous year, and non-Chinese male sexual partners in the previous 6 months (Additional file 1).

Nine relevant questions assessed knowledge of prevention of HIV infection. If the participant answered all questions correctly, we defined them as having an "adequate" knowledge towards the prevention of HIV infection. The questions were as follows: (1) Is it possible for a person who looks healthy to carry HIV? (2) Is it possible to be infected with HIV through transfusion of blood or blood products with HIV? (3) Is it possible to be infected through sharing needles with HIV-infected persons or Acquired Immunodeficiency Syndrome (AIDS) patients? (4) Can the proper use of condoms in each sexual activity reduce the risk of HIV transmission? (5) Can having sex with only a single HIV-uninfected sexual partner reduce the risk of HIV transmission? (6) Can an HIV-infected pregnant woman transmit HIV to her child? (7) Is it possible to be infected through eating with HIV-infected persons or AIDS patients? (8) Is it possible to be infected through mosquito bites? and (9) If you know or suspect that your partner has AIDS, will you stop having sex with him?

Participants were asked about their use (nonmedical or recreational) of seven commonly used RDs at parties or during sexual contact in the previous 6 months: poppers, ecstasy, methamphetamine, amphetamine, codeine, tramadol, and ketamine. We grouped participants based on the number of drugs used in the previous 6 months (i.e., no drug, single drug (1DUs), two types of drugs (2DUs), and $\geq 3$ types of drugs (3DUs)). Use of multiple RDs was defined as use of $\geq 2$ types of drugs in the previous 6 months.

\section{Laboratory testing}

Samples of venous blood were collected from participants to diagnose HIV-1 antibodies. HIV-1 antibodies were detected using enzyme-linked immunosorbent assay [ELISA] (bioMerieux, Durham, NC, USA), and HIV-seropositive specimens were confirmed by western blotting [WB] (HIV Blot 2.2 WBTM, Genelabs Diagnostics, Singapore). The antibody test for HIV was conducted in provincial HIV laboratories of the Chinese Center for Disease Control and Prevention to which the seven study sites were affiliated. These WB-positive samples were tested using HIV-1 subtypes B, E, and D immunoglobulin G (IgG)-capture enzyme immunoassay [BED-CEIA] (Calypte Biomedical Corporation, Rockville, MD, USA) at the Key Laboratory of HIV/AIDS in Shenyang, China. Based on the measurement of HIV-1specific IgG to total IgG after seroconversion, BEDCEIA distinguished between recent and established HIV-1 infections [26, 27]. To test cross-sectional specimens, we followed the algorithm shown in Fig. 1. The calibrator (CAL) and control (including high-positive control, low-positive control, and negative control) specimens were tested in triplicate on each plate, and median values were used to calculate the normalized OD (optical density) (ODn; ODn = specimen $\mathrm{OD} /$ calibrator OD). Specimens with initial ODn $>1.2$ were classified as established infection. Specimens with initial ODn $\leq 1.2$ were tested again in triplicate to confirm their ODn values using the median values of the three obtained values. During the retesting, if median ODn values were $<0.8$, the specimens were considered to be recently infected [28].

\section{Statistical analyses}

We used the chi-square test to determine the significance of differences in sociodemographics of the various subgroups of RD use. We then used the Cochran-Armitage trend test to analyze the association between different subgroups and sociodemographics. We calculated the prevalence, prevalence ratios and 95\% confidence intervals of nine defined HIV-related high-risk behaviors for each subgroup of RD use. An alpha of 0.05 was considered statistically significant. The HIV incidence was estimated using a formula to adjust for sensitivity/specificity, and the time window to define recent HIV infection was up to 168 days. The formula and parameters were recommended by the Chinese Center for Disease Control and Prevention [29]. We then used multivariable 


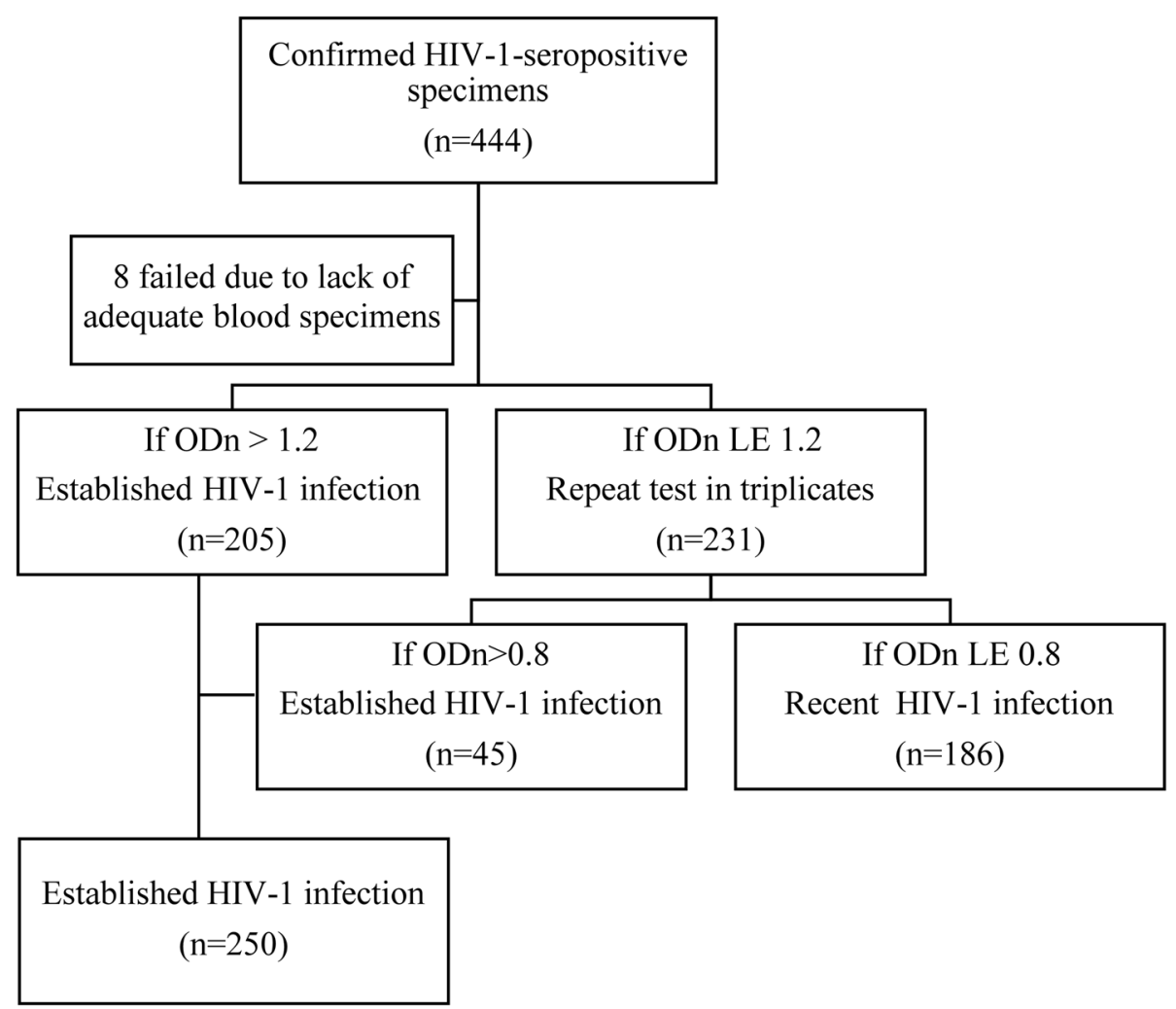

Fig. 1 Algorithm for testing cross-sectional specimens to distinguish between established and recent HIV-1 infection. Abbreviations: OD = optical density

logistic regression to determine the adjusted odds ratios (aOR) and respective 95\% confidence intervals (CIs) of the various subgroups for recent or established HIV infection as defined by the BED-CEIA, adjusting for sociodemographics. Statistical analyses were carried out using SAS 9.2 (SAS Institute, Cary, NC, USA) and STATA 13.0 (Stata Corporation, College Station, TX, USA).

\section{Results}

Prevalence and patterns of use of multiple RDs

In total, 4496 MSM participated in our study. The mean age and standard deviation were $30.2 \pm 5.6$ years, and $1275(28.4 \%)$ reported using RDs in the previous 6 months. Of these, $82.4 \%(n=1050,23.4 \%$ of all participants) used one type of RD (1DUs), $12.2 \%$ ( $n=155,3.4 \%$ of all participants) used two types of RDs (2DUs), and $5.5 \%$ ( $n=70,1.6 \%$ of all participants) used $\geq 3$ types of RDs (3DUs). The prevalence of each unique RD use was as follows: poppers $(25.9 \%)$, ecstasy $(2.4 \%)$, ketamine $(1.2 \%)$, amphetamine $(0.6 \%)$, tramadol $(0.4 \%)$, methamphetamine (3.8\%) and codeine (1.9\%).

Among 1DUs, most used poppers (90.9\%), followed by codeine (3.2\%) and methamphetamine (2.8\%). Among 2DUs, $91.6 \%$ used poppers, $57.4 \%$ used methamphetamines, and 23.9\% used ecstasy. Among 3DUs, 95.7\% used poppers, $74.3 \%$ used methamphetamines, and $71.4 \%$ used ecstasy. Among all participants, 5.0\% ( $n=$ $225,17.6 \%$ of RD users) used two or more RDs (i.e., use of multiple types of RDs). These who used multiple types of RDs commonly took poppers accompanied by one or more types of other RDs (e.g., methamphetamine) (Fig. 2).

\section{Characteristics of the use of multiple types of RDs}

We detected a higher prevalence of RDs use in the previous 6 months among MSM aged 26-30 years (vs. 1825 and $>30$ years; $39.0 \%$ ), among participants who were internal migrants (vs. local cities; $30.1 \%$ ), among those who never married (vs. married; 31.4\%), for those who had a monthly income of $\geq 600$ USD (vs. no income and 1-599 USD; 35.4\%), among those who used several positions during anal intercourse (vs. top or bottom only; $32.2 \%)$, and among those with inadequate knowledge towards HIV-prevention (vs. adequate; $31.8 \%$ ). The proportions of these sociodemographics associated with higher prevalence of RD use increased significantly as the number of RDs used in the previous 6 months increased $(P<0.05$ for trend). Although participants who completed junior school or below had the lowest prevalence for the use of one type of RD in the previous 6 

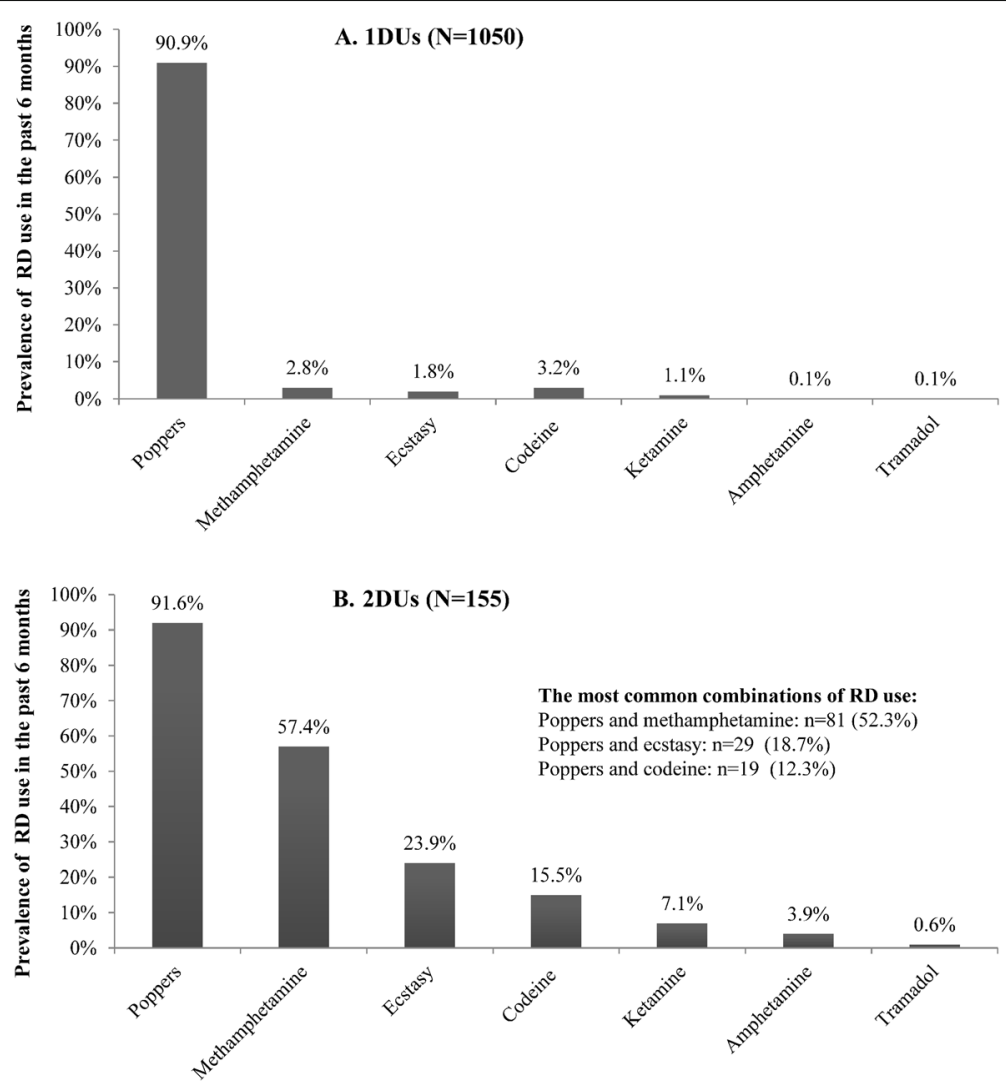

C. 3DUs $(\mathrm{N}=\mathbf{7 0})$

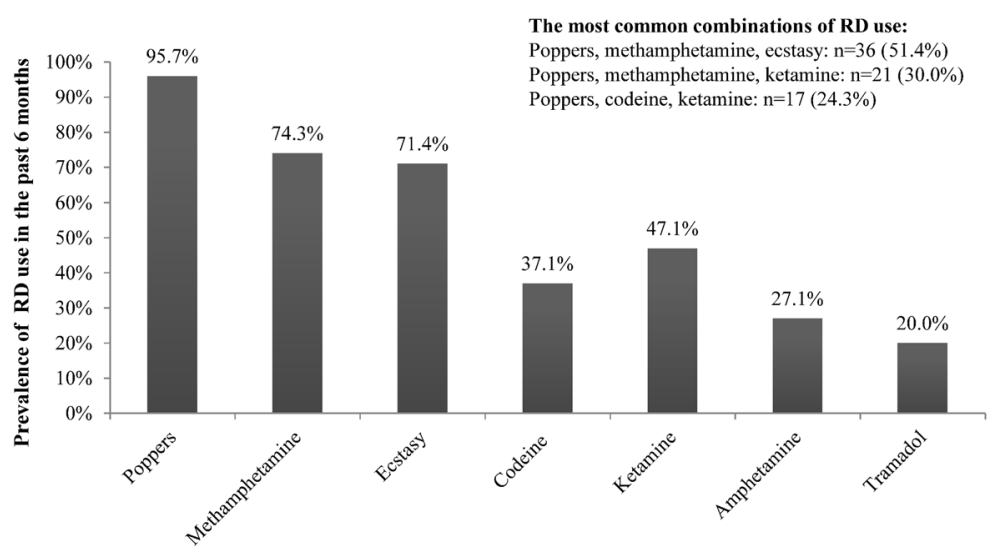

Fig. 2 Prevalence of a specific RD use in the previous 6 months among different subgroups of RD use $(N=4496)$. 1DUs: One type of RD used in the previous 6 months; 2DUs: Two types of RDs used in the previous 6 months; 3DUs: Three or more types of RDs used in the previous 6 months. Out of the 4496 MSM participants, 1050 participants used one type of RD in the previous 6 months (Panel A), 155 used two types of RDs in the previous 6 months (Panel B), and 70 used three or more types of RDs in the previous 6 months (Panel C). The prevalence of the types of most common combinations of RD use are also listed above

months (18.4\%), the prevalence of use of two or more types of RDs in the previous 6 months was significantly higher than (8\%) (Table 1).

\section{Characteristics of HIV-related high-risk behaviors}

For almost all the HIV-related high-risk behaviors examined (e.g., seeking male sexual partners through the
Internet in the previous 6 months, having group sex in the previous 6 months), the prevalence of HIV-related high-risk behavior was higher among those who used RDs in the previous 6 months than in those who did not. There was a significant association between HIV-related high-risk behavior and RD subgroup $(P<0.05$ for all). In general, the prevalence of HIV-related high-risk 
Table 1 Distribution of sociodemographics among different subgroups of RD use $(N=4496)$

\begin{tabular}{|c|c|c|c|c|c|c|}
\hline & $\mathrm{N}$ & ODUs $(n=3221)$ & 1DUs $(n=1050)$ & 2DUs $(n=155)$ & 3DUs $(n=70)$ & $P$ for trend \\
\hline \multicolumn{7}{|l|}{ Age (years) } \\
\hline $18-25$ & 1617 & 1123 & 412 & 59 & 23 & 0.087 \\
\hline $26-30$ & 1181 & 721 & 375 & 63 & 22 & $<0.001$ \\
\hline$>30$ & 1698 & 1377 & 263 & 33 & 25 & $<0.001$ \\
\hline \multicolumn{7}{|l|}{ Residence } \\
\hline Local cities & 1785 & 1327 & 385 & 45 & 28 & 0.002 \\
\hline Non-local cities & 2711 & 1894 & 665 & 110 & 42 & 0.002 \\
\hline \multicolumn{7}{|l|}{ Education } \\
\hline Junior school or below & 916 & 674 & 169 & 45 & 28 & 0.17 \\
\hline High school & 1201 & 877 & 269 & 37 & 18 & 0.227 \\
\hline College or above & 2379 & 1670 & 612 & 73 & 24 & 0.972 \\
\hline \multicolumn{7}{|l|}{ Marital status } \\
\hline Never married & 3303 & 2266 & 860 & 129 & 48 & $<0.001$ \\
\hline Married & 1193 & 955 & 190 & 26 & 22 & $<0.001$ \\
\hline \multicolumn{7}{|l|}{ Occupation } \\
\hline Student & 565 & 418 & 127 & 16 & 4 & 0.058 \\
\hline Non-student & 3931 & 2803 & 923 & 139 & 66 & 0.058 \\
\hline \multicolumn{7}{|l|}{ Monthly income (USD) } \\
\hline No income & 769 & 591 & 146 & 25 & 7 & 0.001 \\
\hline $1-599$ & 2858 & 2069 & 658 & 94 & 37 & 0.042 \\
\hline$\geq 600$ & 869 & 561 & 246 & 36 & 26 & $<0.001$ \\
\hline \multicolumn{7}{|c|}{ Primary sex position during $\mathrm{Al}^{\mathrm{a}}$} \\
\hline Top & 1395 & 1053 & 291 & 34 & 17 & $<0.001$ \\
\hline Bottom & 988 & 725 & 222 & 31 & 10 & 0.067 \\
\hline Versatile & 2022 & 1371 & 527 & 82 & 42 & $<0.001$ \\
\hline \multicolumn{7}{|c|}{ Knowledge of HIV prevention } \\
\hline Inadequate & 2730 & 1861 & 676 & 128 & 65 & $<0.001$ \\
\hline Adequate & 1766 & 1360 & 374 & 27 & 5 & $<0.001$ \\
\hline
\end{tabular}

behaviors increased as the number of RDs used in the previous 6 months increased (Table 2).

\section{Prevalence and incidence of HIV based on RD use}

The HIV prevalence (13.7, 95\% CI: $11.7-15.9$ vs. 8.8 , 95\% CI: 7.8-9.8) and HIV incidence [13.1 infections per 100 person-years, 95\% CI: $9.8-16.3$ vs. 7.7 infections per $100 \mathrm{PY}, 95 \%$ CI: 6.3-9.1] were higher among 1DUs than among participants who did not use RDs in the previous 6 months. By contrast, the HIV prevalence $(8.4,95 \%$ CI: $4.5-13.9 ; 7.1,95 \%$ CI: 2.4-15.9) and HIV incidence (9.7 infections per 100 PY, 95\% CI: 2.5-16.9; 2.4 infections per 100 PY, 95\% CI: $-2.3-7.0$ ) in 2DUs and 3DUs were not significantly higher compared to those who did not use RDs or used one RD in the previous 6 months (Table 3).

\section{Association between RD use and HIV infection}

After adjusting for sociodemographics, 1DUs had higher odds of established HIV infection $(\mathrm{aOR}=2.1,95 \% \mathrm{CI}$ : 1.5-2.8) and higher odds of recent HIV infection $(\mathrm{aOR}=$ 2.2, 95\% CI: 1.5-3.0) than those who did not use RDs. 2DUs also had higher odds of recent HIV infection $(\mathrm{aOR}=2.3,95 \% \mathrm{CI}: 1.0-5.2)$ than those who did not use RDs. In contrast, 2DUs and 3DUs did not have significantly higher odds of established HIV infection than those who did not use RDs (Table 4). 
Table 2 Prevalence and adjusted prevalence ratios of HIV-related high-risk behaviors among different subgroups of RD use ( $N=$ 4496)

\begin{tabular}{lll}
\hline $\begin{array}{l}\text { HIV-related high-risk } \\
\text { behaviors }\end{array}$ & $\mathbf{n} / \mathbf{N}$ & $\begin{array}{l}\text { Prevalence } \\
\%(\mathbf{9 5} \% \mathbf{C l})\end{array}$ \\
\hline $\begin{array}{l}\text { Age of sexual debut with males } \leq \mathbf{2 0} \text { years } \\
\text { ODUs }\end{array}$ & $\begin{array}{l}\text { 1476/3219 } \\
\text { 1DUs }\end{array}$ & $576 / 144.1-47.6)$ \\
2DUs & $105 / 155$ & $54.9(51.9-57.9)$ \\
3DUs & $45 / 70$ & $67.7(60.3-75.2)$ \\
\end{tabular}

Seeking male sexual partners through the Internet in the previous 6 months

$\begin{array}{ll}\text { ODUs } & 2091 / 3221 \\ \text { 1DUs } & 811 / 1050 \\ \text { 2DUs } & 107 / 155 \\ \text { 3DUs } & 46 / 70\end{array}$

$64.9(63.3-66.6)$

Had group sex in the previous 6 months

$\begin{array}{lll}\text { ODUs } & 112 / 3221 & 3.5(2.8-4.1) \\ \text { 1DUs } & 55 / 1050 & 5.2(3.9-6.6) \\ \text { 2DUs } & 6 / 155 & 3.9(0.8-6.9) \\ \text { 3DUs } & 10 / 70 & 14.3(5.9-22.7)\end{array}$

Had more than two male sexual partners in the previous 6 months

$\begin{array}{lll}\text { ODUs } & 1184 / 3220 & 36.8(35.1-38.4) \\ 1 D U s & 490 / 1047 & 46.8(43.8-49.8) \\ 2 D U s & 77 / 155 & 49.7(41.7-57.6) \\ 3 D U s & 34 / 70 & 48.6(36.6-60.6)\end{array}$

Had commercial sex in the previous 6 months

$\begin{array}{lll}\text { ODUs } & 258 / 3221 & 8.0(7.1-8.9) \\ \text { 1DUs } & 136 / 1050 & 13.0(10.9-15.0) \\ \text { 2DUs } & 49 / 155 & 31.6(24.2-39.0) \\ \text { 3DUs } & 16 / 70 & 22.9(12.8-32.9)\end{array}$

Had mucosally traumatic sex in the previous 6 months

$\begin{array}{lll}\text { ODUs } & 459 / 3221 & 14.3(13.0-15.5) \\ \text { 1DUs } & 201 / 1050 & 19.1(16.8-21.5) \\ \text { 2DUs } & 22 / 155 & 14.2(8.6-19.7) \\ \text { 3DUs } & 13 / 70 & 18.6(9.2-27.9)\end{array}$

Had a condom break during $\mathrm{Al}$ in the previous 6 months

$\begin{array}{lll}\text { ODUs } & 255 / 3221 & 7.9(7.0-8.8) \\ \text { 1DUs } & 109 / 1050 & 10.4(8.5-12.2) \\ \text { 2DUs } & 14 / 155 & 9.0(4.5-13.6) \\ \text { 3DUs } & 12 / 70 & 17.1(8.1-26.2)\end{array}$

$1.8(1.2-2.5)$

$2.3(0.9-5.9)$

$5.8(2.4-14.4)$

$<0.001$

$1.6(1.3-1.8)$

$1.3(0.9-1.9)$

$1.3(0.8-2.1)$

$<0.001$

1

$1.2(0.9-1.5)$

$2.0(1.3-3.0)$

$1.3(0.7-2.5)$

0.002

$1.4(1.2-1.8)$

$2.8(1.5-5.1)$

$1.9(0.9-4.0)$

ad STI-related symptom in the previous year

$\begin{array}{lll}\text { ODUs } & 169 / 3221 & 5.2(4.5-6.0) \\ \text { 1DUs } & 81 / 1050 & 7.7(6.1-9.3) \\ \text { 2DUs } & 15 / 154 & 9.7(5.0-14.5) \\ \text { 3DUs } & 11 / 70 & 15.7(7.0-24.5)\end{array}$

$1.3(1.0-1.7)$

$2.3(1.2-4.4)$

$2.6(1.2-5.6)$

$<0.001$

Had non-Chinese male sexual partner in the previous 6 months
ODUs
$30 / 2668$
$1.1(0.7-1.5)$

1

$1.7(1.3-2.3)$

$2.4(1.3-4.5)$

$3.3(1.6-6.8)$

0.039 
Table 2 Prevalence and adjusted prevalence ratios of HIV-related high-risk behaviors among different subgroups of RD use ( $N=$ 4496) (Continued)

\begin{tabular}{llll}
\hline $\begin{array}{l}\text { HIV-related high-risk } \\
\text { behaviors }\end{array}$ & $\mathrm{n} / \mathbf{N}$ & $\begin{array}{l}\text { Prevalence } \\
\%(\mathbf{9 5 \%} \mathrm{Cl})\end{array}$ & $\begin{array}{l}\text { Adjusted prevalence ratios }^{\mathbf{a}} \\
\mathbf{( 9 5 \% ~ C l )}\end{array}$ \\
\hline 1DUs & $17 / 867$ & $2.0(1.0-2.9)$ & $2.4(1.2-4.5)$ \\
2DUs & $5 / 138$ & $3.6(0.5-6.8)$ & $10.0(3.1-31.9)$ \\
3DUs & $1 / 51$ & $2.0(0.0-5.9)$ & $6.6(0.7-59.1)$ \\
\hline
\end{tabular}

ODUs No RDs used in the previous 6 months, 1DUs One type of RD used in the previous 6 months, 2DUs Two types of RDs used in the previous 6 months, 3DUs Three or more types of RDs used in the previous 6 months, $A l$ anal intercourse; Commercial sex: buying or selling sex services, including anal intercourse or oral intercourse; STI-related symptoms: abnormal pain or burning sensation upon micturition, urethra secretion, genital/anal skin damage, or hyperplasia; Mucosally traumatic sex: Mucosally traumatic sex means sexual intercourse especially anal intercourse sometimes may be rougher or last for longer and caused vagina, anus, or rectum mucosal trauma, which could facilitate HIV/STIs transmission. The table includes information only for participants who answered a specific question so that sample sizes may differ because of missing data. Unadjusted $P$-values were calculated by the chi-squared test. a: Adjusted prevalence ratios were calculated through multivariable log-binomial regression adjusting for the following sociodemographics: study site (Shanghai, Nanjing, Changsha, Zhengzhou, Ji'nan, Shenyang, and Kunming), age (18-25, 26-30, and $>30$ years), residence (local cities and non-local cities), education (junior school or below, high school, and college or above), marital status (never married and married), occupation (student and non-student), monthly income (no income, 1-599, and $\geq 600$ USD), primary sex position during Al (top, bottom, and versatile), and knowledge of HIV prevention (inadequate and adequate)

\section{Discussion}

We examined patterns of use of RDs among Chinese MSM and the impact of such RD use on HIV-related high-risk behaviors and HIV acquisition. We found that the prevalence of use of multiple RDs among Chinese MSM (5.0\%) was lower than the reported prevalence of use of multiple RDs among MSM in western highincome countries (11.8\%) [2]. Chinese MSM who used multiple RDs frequently used poppers along with one or more types of other RDs. As the number of RDs used in the previous 6 months increased, the prevalence of various HIV-related high-risk behaviors also increased. The odds of recent HIV infection were higher among those who used RDs in the previous 6 months than among those who did not. These data suggest that those who use multiple RDs are substantially more likely to engage in risky sexual behaviors and may have a higher risk of HIV acquisition.

Our findings expand the understanding of the RD use in MSM in a low-to-middle income country and the relationship of multiple RD use with HIV infection. Previous studies showed correlations between RD use and HIV-related high-risk behaviors among MSM [6, 30]. Our study confirmed those results and found that the increase in the number of RDs used was associated with an increase in the prevalence of HIV-related high-risk behaviors. A similar finding was documented among HIV-positive MSM in the United Kingdom [16]; however, until now, this relationship has not been examined in a low-to-middle income country. In contrast with patterns of use of multiple RDs among MSM in highincome countries who frequently use $[16,17,31]$, Chinese MSM frequently use poppers. We found that $90 \%$ of MSM used poppers, and those who used multiple RDs frequently used poppers and one or more types of other RDs (i.e., methamphetamine, ecstasy, codeine, or ketamine). Poppers are physiologically active substances that facilitate and enhance anal intercourse $[2,12]$. They do not directly affect mental function or decision-making [32]. However, when poppers were used with other psychoactive drugs [2] such as methamphetamine, ecstasy, or ketamine, the prevalence of HIV-related high-risk behaviors increased significantly (Table 2). Most psychoactive drugs are stimulants and, thus, can alter the mental state [15], cause loss of muscle control [15], enhance sexual desires/sexual functions, and affect risk perception and decision-making $[10,11]$. If psychoactive drugs are used simultaneously with poppers (which relax

Table 3 HIV prevalence and BED-CEIA-based HIV incidence among Chinese MSM participants ( $N=4496)$

\begin{tabular}{lllllll}
\hline & Total & $\begin{array}{l}\text { HIV } \\
\text { infection }\end{array}$ & $\begin{array}{l}\text { HIV recent } \\
\text { infection }\end{array}$ & $\begin{array}{l}\text { HIV established } \\
\text { infection }\end{array}$ & $\begin{array}{l}\text { HIV prevalence (\%) } \\
\mathbf{( 9 5 \% ~ C l ) ~}^{\mathbf{a}}\end{array}$ & $\begin{array}{l}\text { HIV incidence (per 100 } \\
\text { PY) (95\% CI) }\end{array}$ \\
\hline $\begin{array}{l}\text { Subgroups of RD } \\
\text { use }\end{array}$ & 4496 & 444 & 186 & 250 & $9.9(9.0-10.8)$ & $8.9(7.6-10.2)$ \\
ODUs & 3221 & 282 & 116 & 161 & $8.8(7.8-9.8)$ & $7.7(6.3-9.1)$ \\
1DUs & 1050 & 144 & 62 & 79 & $13.7(11.7-15.9)$ & $13.1(9.8-16.3)$ \\
2DUs & 155 & 13 & 7 & 6 & $8.4(4.5-13.9)$ & $9.7(2.5-16.9)$ \\
3DUs & 70 & 5 & 1 & 4 & $7.1(2.4-15.9)$ & $2.4(-2.3$ to 7.0$)$ \\
\hline
\end{tabular}

ODUs No RDs used in the previous 6 months, 1DUs One type of RD used in the previous 6 months, 2DUs Two types of RDs used in the previous 6 months, 3DUs Three or more types of RDs used in the previous 6 months. ${ }^{a}$ HIV prevalence was calculated from all HIV infections (i.e., recent and established) diagnosed through the study. The BED-CEIA could not be conducted on samples from eight HIV antibody-positive participants because of insufficientblood specimens. ${ }^{\mathrm{b}}$ The HIV incidence determined using the BED-CEIA was then adjusted using the sensitivity and specificity adjustment formula and parameters recommended by the Chinese Center for Disease Control and Prevention 
Table 4 Adjusted odds ratios for recent or established HIV infections stratified by RD use subgroup $(N=4488)^{\text {a }}$

\begin{tabular}{|c|c|c|c|c|c|c|c|}
\hline \multirow{3}{*}{$\begin{array}{l}\text { Subgroups } \\
\text { of } R D \text { use }\end{array}$} & \multirow[t]{3}{*}{ Total } & \multicolumn{3}{|c|}{ Recent HIV infection $(N=186)$} & \multicolumn{3}{|c|}{ Established HIV infection $(N=250)$} \\
\hline & & n (\%) & Adjusted model $^{b}$ & $P$ & n (\%) & Adjusted model $^{b}$ & $P$ \\
\hline & & & aOR $(95 \% \mathrm{Cl})$ & & & aOR $(95 \% \mathrm{Cl})$ & \\
\hline ODUs & 3216 & $116(3.6)$ & 1 & - & $161(5.0)$ & 1 & - \\
\hline 1DUs & 1047 & $62(5.9)$ & $2.2(1.5-3.0)$ & $<0.001$ & $79(7.5)$ & $2.1(1.5-2.8)$ & $<0.001$ \\
\hline 2DUs & 155 & $7(4.5)$ & $2.3(1.0-5.2)$ & 0.054 & $6(3.9)$ & $1.4(0.6-3.4)$ & 0.433 \\
\hline 3DUs & 70 & $1(1.4)$ & $0.8(0.1-5.8)$ & 0.809 & $4(5.7)$ & $1.9(0.6-5.4)$ & 0.247 \\
\hline
\end{tabular}

ODUs No RDs used in the previous 6 months, 1DUs One type of RD used in the previous 6 months, 2DUs Two types of RDs used in the previous 6 months, $3 D U s$

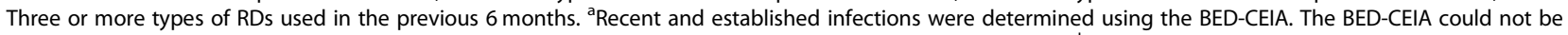
conducted on samples from eight HIV antibody-positive participants because of insufficient blood specimens. ${ }^{\mathrm{b}}$ Adjusted odds ratios (aOR) and the corresponding $95 \% \mathrm{Cl}$ were derived through multivariable logistic regression analysis with adjustment for the following social demographics: study site (Shanghai, Nanjing,

Changsha, Zhengzhou, Ji'nan, Shenyang, and Kunming), age (18-25, 26-30, and > 30 years), residence (local cities and non-local cities), education (junior school or below, high school, and college or above), marital status (never married and married), occupation (student and non-student), monthly income (no income, 1-599, and $\geq 600$ USD), primary position during $\mathrm{Al}$ (top, bottom, and versatile), and knowledge of HIV prevention (inadequate and adequate)

the anal-sphincter muscles and reduce pain), MSM can experience more serious sexual disinhibition and, thus, anal intercourse may be more robust or last longer, leading to increased risk of HIV infection [32]. This pattern of use of multiple RDs is widespread among Chinese MSM and was associated with more HIV-related highrisk behaviors in our study. Scholars also found that using poppers with methamphetamine or amphetamine was associated with more unprotected sex acts [33] and, hence, was linked to a higher risk of HIV seroconversion $[34,35]$.

The proportion of HIV-related high-risk behaviors increased as the number of RDs used in the previous 6 months increased. However, possible relationship between HIV-related high-risk behaviors, the number of RDs used, and HIV infections are not clear. When we subdivided diagnosed HIV infections into recent and established HIV infections based on the BED-CEIA, we found a significant relationship between higher odds of recent HIV infection and one type of RD used or two types of RD used compared with no RD used in the previous 6 months. While we did not find a significant relationship between higher odds of recent HIV infection and 3DUs compared to those who did not use RDs, this finding could have been due to our small sample size and low statistical power to detect the differences in our aOR estimates. In contrast, we found a significant relationship between established HIV infection and one type of RD used in the previous 6 months compared with no $\mathrm{RD}$ use. This result suggests that RDs used in the previous 6 months were associated in particular with recent HIV infection. This may have been because those use multiple RDs are less risk-averse and more likely to engage in more risky sexual behaviors and, thus, may have higher risk of new HIV infections. [41, 42] Several longitudinal studies found similar associations between the use of multiple RDs and recent HIV seroconversion [18, 36]. Newly infected individuals have high levels of viral load in plasma and few pronounced symptoms and are highly infectious; However, identifying newly infected individuals is difficult $[37,38]$. MSM in this HIV seroconversion period have been found to participate frequently in HIV-related high-risk behaviors [38]. Thus, those who use multiple RDs likely take more sexual risks and therefore may have an increased risk of secondary HIV transmission.

Although the prevalence of use of multiple RDs among Chinese MSM in our study was lower than the prevalence among MSM reported in high-income countries $(5.0 \%$ vs. $11.8 \%)$ [2], the actual prevalence of use of multiple RDs of Chinese MSM may have been underestimated. First, most RDs are illegal in China, so participants may have been afraid of the repercussions of answering honestly about their use of multiple RDs. To address these fears, we used an anonymous survey to minimize this social desirability bias. Second, we investigated only the seven most commonly used RDs among Chinese MSM. There are many more RD used by MSM that we did not address in this study.

We elucidated the characteristics and possible mechanisms of HIV transmission among Chinese MSM who use RDs. We undertook this study in the hope of developing targeted interventions to address the HIV epidemic. We found that participants aged 26-30 years had a higher prevalence of overall RD use in the previous 6 months (39.0\%) and use of multiple RDs in the previous 6 months (7.2\%) compared with any other age group examined. The number of identified HIV/AIDS cases among MSM aged 26-30 years in China increased rapidly from 2007 to 2015 [39]. Mao and colleagues found a high HIV incidence ( 9 infections per $100 \mathrm{PY})$ among Chinese MSM aged 26-30 years [40]. RD use was associated with behaviors that increase the risk of HIV, suggesting that tailored methods reducing $\mathrm{RD}$ use implemented among Chinese MSM 26-30 years old could reduce the risk of HIV acquisition. We also found 
an association between inadequate knowledge of HIV prevention and an increase in the number of RDs used in the previous 6 months, suggesting that strategies focused on increasing positive attitude towards prevention of HIV infection should be targeted at those who use multiple RDs. Finally, many Chinese MSM in our study used poppers, which may have been due to the ease of buying this drug as it is legal in China [19]. We suggest that the Chinese government restrict the sale of poppers to reduce $\mathrm{RD}$ use and decrease the effect of RD use on HIV transmission.

One limitation or our study was the few participants who self-reported using multiple types of RDs (5.0\%). The few participants in this category likely reduced the power of our study to detect differences in the different drug use sub-groups. We also did not collect the link-to-care details of the participants diagnosed with HIV in this study. However, China has already established a standard procedure for individuals diagnosed with HIV to obtain free antiretroviral therapy (ART) treatment and follow-up testing. Once a person was diagnosed with HIV in this study, the local Chinese Center for Disease Control and Prevention would refer him to the local infectious disease hospital to obtain free ART treatment. The government would allocate ART treatment medications and pay for the costs of follow-up tests.

\section{Conclusions}

Chinese MSM who used multiple RDs frequently used poppers along with one or more types of other RDs. The proportion of HIV-related high-risk behaviors increased as the number of RD used in the previous 6 months increased. Using one or two types of RDs was associated with increased odds of recent HIV infection among Chinese MSM compared to the odds of those who did not use RDs. Therefore, the use of several types of RDs is likely associated with new HIV infections. Strategies focusing on decreasing RD use among Chinese MSM and increased governmental control of RDs could reduce drug use and mitigate the HIV epidemic in China.

\section{Supplementary Information}

The online version contains supplementary material available at https://doi. org/10.1186/s12889-021-10223-y.

Additional file 1. Questionnaire developed for this study

\section{Abbreviations}

MSM: Men who have sex with men; HIV: Human immunodeficiency virus; RDs: Recreational drugs; HIV-HRBs: HIV high-risk behaviors; CLS: Condomless sex; WB: Western blotting; BED-CEIA: Immunoglobulin G (lgG)-capture BEDenzyme immunoassay; Cls: Confidence intervals; AORs: Adjusted odds ratios; ORs: Odds ratios; 1DUs: Users of one type of RD; 2DUs: Users of two types of RDs; 3DUs: Users of three or more types RDs

\section{Acknowledgements}

Not Applicable.

\section{Authors' contributions}

Conception and design of experiments: XM, HS, JJX, QHH; carried out the study and experiments: HJY, ZW, LL, MHZ, XC, JHF, WQG, YJJ; analyzed the data: XM, QHH, JJX; wrote and revised the manuscript: XM, SIL, JJX. All authors reviewed the manuscript.

\section{Funding}

This study was funded by the Mega-Projects of National Science Research (13th Five-Year Plan [2017ZX10201101-002-007]) and National Natural Science Foundation of China (81872674), National Science and Technology Major Project (2018ZX10101-001-001-003), and Central Public-Interest Scientific Institution Basal Research Fund of Chinese Academy of Medical Sciences (2018PT31042). The funding bodies played no role in the design of the study and collection, analysis, and interpretation of data and in writing the manuscript.

\section{Availability of data and materials}

Data on this research is available with the corresponding author.

\section{Ethics approval and consent to participate}

The Ethics Review Board approved the study protocol of the First Affiliated Hospital of China Medical University ([2011]-36; Shenyang, China). The study was undertaken following all relevant guidelines and regulations. Written informed consent was obtained from all participants before study commencement.

The participants included in this study gave their consent for using anonymized direct quotes in this manuscript.

\section{Competing interests}

The authors declare that they have no conflict of interest.

\section{Author details}

${ }^{1} \mathrm{NHC}$ Key Laboratory of AIDS Immunology (China Medical University), National Clinical Research Center for Laboratory Medicine, The First Affiliated Hospital of China Medical University, No 155, Nanjing North Street, Heping District, Shenyang 110001, Liaoning Province, China. ${ }^{2}$ Key Laboratory of AIDS Immunology, Chinese Academy of Medical Sciences, Shenyang 110001, China. ${ }^{3}$ Key Laboratory of AIDS Immunology of Liaoning Province, Shenyang 110001, China. ${ }^{4}$ Collaborative Innovation Center for Diagnosis and Treatment of Infectious Diseases, 79 Qingchun Street, Hangzhou 310003, China. ${ }^{5}$ Department of Epidemiology University of North Carolina at Chapel Hill NC Chapel Hill USA. Jiangsu Provincial Centers for Disease Control and Prevention, Nanjing 210009, China. ${ }^{7}$ He'nan Provincial Centers for Disease Control and Prevention, Zhengzhou 450022, China. ${ }^{8}$ Yunnan Provincial Centers for Disease Control and Prevention, Kunming 650022, China. ${ }^{9}$ Shanghai Municipal Centers for Disease Control and Prevention, Shanghai 200336, China. ${ }^{10}$ Hu'nan Provincial Centers for Disease Control and Prevention, Changsha 410005, China. ${ }^{11}$ Shandong Provincial Centers for Disease Control and Prevention, Jinan 250014, China.

Received: 9 August 2019 Accepted: 12 January 2021

Published online: 15 February 2021

\section{References}

1. UNAIDS. UNAIDS data 2019. 2019. http://www.unaids.org/sites/default/files/ media_asset/2019-UNAIDS-data_enpdf. Accessed 5 June 2019.

2. Rosinska M, Gios L, Nostlinger C, Vanden Berghe W, Marcus U, Schink S, et al. Prevalence of drug use during sex amongst MSM in Europe: results from a multi-site bio-behavioural survey. Int J Drug Policy. 2018;55:231-41.

3. Xu JJ, Qian HZ, Chu ZX, Zhang J, Hu QH, Jiang YJ, et al. Recreational Drug Use among Chinese Men Who Have Sex with Men: A Risky Combination with Unprotected Sex for Acquiring HIV Infection. Biomed Res Int. 2014; 2014:725361.

4. Lampinen TM, Mattheis K, Chan K, Hogg RS. Nitrite inhalant use among young gay and bisexual men in Vancouver during a period of increasing HIV incidence. BMC Public Health. 2007;7:35.

5. Feng SH. Rethinking China's drug control policy under the background of new drug subculture. J Shanxi Police Coll. 2019;27:67-71. 
6. Drumright LN, Patterson TL, Strathdee SA. Club drugs as causal risk factors for HIV acquisition among men who have sex with men: a review. Subst Use Misuse. 2006;41:1551-601.

7. Chen X, Li XL, Zheng J, Zhao JS, He JM, Zhang GQ, et al. Club drugs and HIV/STD infection: an exploratory analysis among men who have sex with men in Changsha, China. PLoS One. 2015:10:e0126320.

8. Nguyen TV, Van Khuu N, Nguyen PD, Tran HP, Phan HTT, Phan LT, et al. Sociodemographic factors, sexual behaviors, and alcohol and recreational drug use associated with HIV among men who have sex with men in southern Vietnam. AIDS Behav. 2016;20:2357-71.

9. Bautista CT, Sanchez JL, Montano SM, Laguna-Torres VA, Lama JR, Sanchez $J$, et al. Seroprevalence of and risk factors for HIV-1 infection among south American men who have sex with men. Sex Transm Infect. 2004;80:498504.

10. Kurtz SP. Post-circuit blues: motivations and consequences of crystal meth use among gay men in Miami. AIDS Behav. 2005;9:63-72.

11. Green Al. "Chem friendly": the institutional basis of "club-drug" use in a sample of urban gay men. Deviant Behav. 2003;24:427-47.

12. Romanelli F, Smith KM, Thornton AC, Pomeroy C. Poppers: epidemiology and clinical management of inhaled nitrite abuse. Pharmacotherapy. 2004; 24:69-78.

13. Ross MW, Mattison AM, Franklin DR. Club drugs and sex on drugs are associated with different motivations for gay circuit party attendance in men. Subst Use Misuse. 2003;38:1173-83.

14. Gorman EM, Applegate T, Scrol A. Club drug and poly-substance abuse and HIV among gay/bisexual men. J Gay Lesbian Soc Serv. 2003;16:1-17.

15. Freese TE, Miotto K, Reback CJ. The effects and consequences of selected club drugs. J Subst Abus Treat. 2002;23:151-6.

16. Daskalopoulou M, Rodger A, Phillips AN, Sherr L, Speakman A, Collins S, et al. Recreational drug use, polydrug use, and sexual behaviour in HIVdiagnosed men who have sex with men in the UK: results from the crosssectional ASTRA study. Lancet HIV. 2014;1:E22-31.

17. Sewell J, Miltz A, Lampe FC, Cambiano V, Speakman A, Phillips AN, et al. Poly drug use, chemsex drug use, and associations with sexual risk behaviour in HIV-negative men who have sex with men attending sexual health clinics. Int J Drug Policy. 2017:43:33-43.

18. Ostrow DG, Plankey MW, Cox C, Li XH, Shoptaw S, Jacobson LP, et al. Specific sex drug combinations contribute to the majority of recent HIV Seroconversions among MSM in the MACS. J Acquir Immune Defic Syndr. 2009:51:349-55.

19. Zhang H, Tenga T, Lu HY, Zhao YJ, Liu HJ, Yin L, et al. Poppers use and risky sexual behaviors among men who have sex with men in Beijing, China. Drug Alcohol Depend. 2016;160:42-8.

20. Beyrer C, Baral SD, van Griensven F, Goodreau SM, Chariyalertsak S, Wirtz AL, et al. Global epidemiology of HIV infection in men who have sex with men. Lancet. 2012;380:367-77.

21. Tang SY, Tang WM, Meyers K, Chan P, Chen ZD, Tucker JD. HIV epidemiology and responses among men who have sex with men and transgender individuals in China: a scoping review. BMC Infect Dis. 2016;16: 588.

22. China Youth Daily. By the end of 2017, there were 2.553 million drug addicts nationwide. 2018. http://news.cyol.com/yuanchuang/2018-06/25/ content 17322252htm. Accessed 5 June 2019.

23. Wang Z, Li D, Lau JT, Yang X, Shen H, Cao W. Prevalence and associated factors of inhaled nitrites use among men who have sex with men in Beijing, China. Drug Alcohol Depend. 2015;149:93-9.

24. Zhao P, Tang S, Wang C, Zhang Y, Best J, Tangthanasup TM, et al. Recreational drug use among Chinese MSM and transgender individuals: results from a National Online Cross-Sectional Study. PLoS One. 2017;12: e0170024.

25. Chen $H$, Yang $Y$, Huang $Y$, Dai $Y$, Zhang J. Prevalence of poppers use and its sexual risks among men who have sex with men in southwestern China: a cross-sectional study. BMC Public Health. 2018;18:1103.

26. Parekh BS, Kennedy MS, Dobbs T, Pau CP, Byers R, Green T, et al. Quantitative detection of increasing HIV type 1 antibodies after seroconversion: a simple assay for detecting recent HIV infection and estimating incidence. AIDS Res Hum Retrovir. 2002;18:295-307.

27. Dobbs T, Kennedy S, Pau CP, McDougal JS, Parekh BS. Performance characteristics of the immunoglobulin G-capture BED-enzyme immunoassay, an assay to detect recent human immunodeficiency virus type 1 seroconversion. J Clin Microbiol. 2004;42:2623-8.
28. Yan $H, Y u H$, Xing $W$, Xiao $Y$, Zhang $H$, Pei L, et al. Development of a proficiency testing program for the HIV-1 BED incidence assay in China. Sci Rep. 2014;4:4512.

29. China CDC. National Guidelines for serology-based detection of HIV-1 incidence in China. 2011. http://ncaids.chinacdc.cn/fzyw_10256/jsgf/201608/ W020171101497393625088.pdf, Accessed 2 Dec 2018.

30. Bourne A, Weatherburn P. Substance use among men who have sex with men: patterns, motivations, impacts and intervention development need. Sex Transm Infect. 2017;93:342-6.

31. Halkitis PN, Palamar JJ, Mukherjee PP. Poly-club-drug use among gay and bisexual men: a longitudinal analysis. Drug Alcohol Depend. 2007;89:153-60.

32. French RS, Power R. Self-reported effects of alkyl nitrite use: a qualitative study amongst targeted groups. Addict Res. 1997:5:519-48.

33. Semple SJ, Strathdee SA, Zians J, Patterson TL. Sexual risk behavior associated with co-administration of methamphetamine and other drugs in a sample of HIV-positive men who have sex with men. Am J Addict. 2009; 18:65-72.

34. Plankey MW, Ostrow DG, Stall R, Cox C, Li XH, Peck JA, et al. The relationship between methamphetamine and popper use and risk of HIV seroconversion in the multicenter AIDS cohort study. J Acquir Immune Defic Syndr. 2007;45:85-92

35. Ackers ML, Greenberg AE, Lin CY, Bartholow BN, Goodman AH, Longhi M, et al. High and persistent HIV Seroincidence in men who have sex with men across 47 US cities. PLoS One. 2012;7:e34972

36. Carey JW, Mejia R, Bingham T, Ciesielski C, Gelaude D, Herbst JH, et al. Drug use, high-risk sex behaviors, and increased risk for recent HIV infection among men who have sex with men in Chicago and Los Angeles. AIDS Behav. 2009;13:1084-96

37. Buskin SE, Fida NG, Bennett AB, Golden MR, Stekler JD. Evaluating new definitions of acute and early HIV infection from HIV surveillance data. Open AIDS J. 2014:8:45-9.

38. Colfax GN, Buchbinder SP, Cornelisse PGA, Vittinghoff E, Mayer K, Celum C. Sexual risk behaviors and implications for secondary HIV transmission during and after HIV seroconversion. AIDS. 2002;16:1529-35.

39. Qin QQ, Guo W, Tang WM, Mahapatra T, Wang LY, Zhang NC, et al. Spatial analysis of the human immunodeficiency virus epidemic among men who have sex with men in China, 2006-2015. Clin Infect Dis. 2017:64:956-63.

40. Mao X, Wang Z, Hu Q, Huang C, Yan H, Wang Z, et al. HIV incidence is rapidly increasing with age among young men who have sex with men in China: a multicentre cross-sectional survey. HIV Med. 2018;19:513-22.

\section{Publisher's Note}

Springer Nature remains neutral with regard to jurisdictional claims in published maps and institutional affiliations.
Ready to submit your research? Choose BMC and benefit from:

- fast, convenient online submission

- thorough peer review by experienced researchers in your field

- rapid publication on acceptance

- support for research data, including large and complex data types

- gold Open Access which fosters wider collaboration and increased citations

- maximum visibility for your research: over $100 \mathrm{M}$ website views per year

At $\mathrm{BMC}$, research is always in progress.

Learn more biomedcentral.com/submissions 